\title{
Maternal Thyroid Function During Pregnancy and Behavioral Problems in the Offspring: The Generation R Study
}

\author{
AKHGAR GHASSABIAN, JACOBA J. BONGERS-SCHOKKING, JENS HENRICHS, VINCENT W.V. JADDOE, THEO J. VISSER, \\ WILLY VISSER, SABINE M.P.F. DE MUINCK KEIZER-SCHRAMA, HERBERT HOOIJKAAS, ERIC A.P. STEEGERS, \\ ALBERT HOFMAN, FRANK C. VERHULST, JAN VAN DER ENDE, YOLANDA B. DE RIJKE, AND HENNING TIEMEIER
}

The Generation R Study [A.G.], and Departments of Epidemiology [V.V.W.J., A.H., H.T.], Internal Medicine [T.J.V., Y.B.R.], and Immunology [H.H.], Erasmus Medical Center, 3000 CA Rotterdam, The Netherlands; Institute of Psychology [J.H.], Erasmus University, 3000 DR Rotterdam, The Netherlands; Departments of Child and Adolescent Psychiatry [A.G., F.C.V., J.E., H.T.], Endocrinology [J.J.B.-S, S.M.P.F.M.K.-S.], Pediatrics [V.V.W.J.], Obstetrics and Gynecology [W.V., E.A.P.S.], and Clinical Chemistry [Y.B.R.], Erasmus Medical Center-Sophia Children's Hospital, 3000 CB Rotterdam, the Netherland

\begin{abstract}
Maternal thyroid function during pregnancy is implicated in the neurodevelopment of the offspring, yet little is known about the effect of maternal thyroid parameters on the behavior of children. We investigated the association of maternal thyroid function during the first half of pregnancy with parent-reported problem behavior of the offspring up to age of $3 \mathrm{y}$. In the Generation R study, a population-based cohort of 3736 children and their mothers, data on maternal thyroid function and child's behavior were examined. The degree of internalizing and externalizing problems in the children were assessed with the Child Behavior Checklist at ages $1 \frac{1}{2}$ and $3 \mathrm{y}$. Higher levels of maternal TSH during pregnancy predicted a higher externalizing scores in children at $1 \frac{1}{2} 2$ and $3 \mathrm{y}(B=0.22$ per SD of TSH; 95\% CI: $0.04,0.40 ; B=0.10$ per SD for internalizing scores; $95 \% \mathrm{CI}$ : $-0.01,0.21)$. Maternal free thyroxine (T4) and total $\mathrm{T} 4$ were not associated with internalizing or externalizing scores of children. The linear relationship with more externalizing scores was across the range of TSH; this implies that subtle impairments of maternal thyroid function may affect the child. The results suggest that thyroid function is crucial for fetal brain development, which determines problem behavior later in life. (Pediatr Res 69: 454-459, 2011)
\end{abstract}

$\mathrm{T}$ hyroid hormones are crucial for the development of the fetal brain. More than $30 \mathrm{y}$ ago, Man and Jones (1) and Man and Serunian (2) suggested that maternal thyroid hormones during pregnancy play an important role in the neuropsychological development of the child. Animal studies provided evidence for the role of thyroid hormones in normal cytoarchitecture of the

Received June 7, 2010; accepted December 7, 2010.

Correspondence: Henning Tiemeier, M.D., Ph.D., Department of Child and Adolescent Psychiatry, Erasmus MC University Medical Center Rotterdam-Sophia Children Hospital, P.O. Box 2060, 3000 CB Rotterdam, The Netherlands; e-mail: h.tiemeier@erasmusmc.nl

Supported by a research grant from the European Community's 7th Framework Programme (FP7/2008-2013) under grant agreement 212652 (NUTRIMENTHE project, "The Effect of Diet on the Mental Performance of Children") to H.T.

The Generation R study is conducted by Erasmus Medical Center Rotterdam in close collaboration with the faculty of Social Sciences of Erasmus University Rotterdam, the Municipal Health Service Rotterdam area, the Rotterdam Homecare Foundation and the Stichting Trombosedienst \& Artsenlaboratorium Rijnmond (STAR), Rotterdam. The first phase of Generation R was supported by Erasmus Medical Center Rotterdam, the Erasmus University Rotterdam, and the Netherlands Organization for Health Research and Development (ZonMw 10.000.1003). Measurements of thyroid parameters have been made possible by a generous financial gift of Ortho Clinical Diagnostics, Rochester, NY, and Jan Dekker/ Ludgardine Bouwman Foundation, Fa. Merck, and Foundation Zeist.

This study was part of the Master of Science program by the Netherlands Institute for Health Sciences (Nihes). brain (3). During early gestation, the fetus depends entirely on maternal thyroid hormones as the fetal thyroid function does not begin before 12-14 wk of pregnancy $(4,5)$. Even after the onset of fetal thyroid hormone production, the fetus continues to rely on maternal thyroid function (5).

Against this background, several groups investigated the effect of maternal thyroid dysfunction in pregnancy on neurodevelopment of the offspring (6-8). Haddow et al. (7) showed that during early pregnancy, hypothyroidism is associated with poor cognitive function and low intelligence quotient (IQ) in the offspring. Pop et al. $(9,10)$ indicated that subtle changes in maternal thyroid function during pregnancy may predict poor psychomotor and cognitive development in children. However, there is little information on the role of maternal thyroid function in pregnancy for child's behavior. Vermiglio et al. (8) investigated the behavioral problems of children in the context of iodine insufficiency. In a study of 27 subjects, they reported an abnormally high frequency of Attention Deficit/Hyperactivity Disorders in children whose mothers were hypothyroxinemic during pregnancy. In addition, they showed that children's IQ score was inversely related to maternal TSH levels in mid gestation.

We performed a prospective population-based study with repeated measurement of problem behavior in children up to age $3 \mathrm{y}$. Maternal thyroid function [free thyroxine (T4), total $\mathrm{T} 4$, and TSH] was assessed before the 18th week of gestation to investigate the association of maternal thyroid function with internalizing and externalizing problem scores as indicators of offspring's neurodevelopment later in life.

\section{METHODS}

Setting. This study was embedded in Generation R, a population-based cohort in Rotterdam from early fetal life onward $(11,12)$. Mothers with a delivery date between April 2002 and January 2006 were enrolled. The study was approved by the Medical Ethics Committee of the Erasmus Medical Center, Rotterdam. Written informed consent was obtained from all adult participants.

Abbreviations: CBCL, The Child Behavior Checklist; DSM, Diagnostic and Statistical Manual of Mental Disorder; GEE, Generalized Estimating Equation; T4, thyroxine 
Subjects. We measured one or more thyroid parameters in 4892 pregnant women before 18th week of gestation. Thirty-six pregnant women were excluded because of the current use of thyroid medication. Of the 4856 remaining women, 3369 mothers completed the Child Behavior Checklist (CBCL) for their children at the age of $1 \frac{1}{2} \mathrm{y}$. At age $3 \mathrm{y}$, the CBCL was completed by 3177 mothers and 2658 fathers. In total, 3736 children $(77 \%)$ with maternal thyroid and behavioral data were included in one or more analysis.

Maternal thyroid parameters. We assessed maternal thyroid parameters in pregnancy at the first prenatal visit. The GA at the time of blood sampling was $<18 \mathrm{wk}$ in all participants (mean $=13.3 \mathrm{wk}, \mathrm{SD}=1.7$ ). Within $24 \mathrm{~h}$ after sampling, the plasma was stored at $-70^{\circ} \mathrm{C}$. The $\mathrm{TSH}$, free and total $\mathrm{T} 4$ were determined in the stored samples in batches over a 6-mo period, using chemiluminescence assays (Vitros ECI Immunodiagnostic System Ortho Clinical Diagnostics, Rochester, NY). Reference values of free and total T4 for nonpregnant women in our laboratory were $11-25 \mathrm{pmol} / \mathrm{L}$ and $58-128$ $\mathrm{nmol} / \mathrm{L}$. The interassay and intra-assay coefficients of variation for free T4 were $4.7-5.4 \%$ and $1.4-2.7 \%$. The respective coefficients for total T4 were $4.6-6.4 \%$ and $2.6-2.7 \%$. To obtain pregnancy reference ranges, the normal population reference ranges for total T4 were multiplied by 1.5 as recommended by Endocrine Society Clinical Practice Guideline (6). The interassay and intra-assay coefficients of variation for TSH were $2.5-4.1 \%$ and $1.0-$ $1.2 \%$. Hypothyroxinemia was defined as TSH levels within the reference range for pregnancy $(>0.03 \mathrm{mIU} / \mathrm{L}$ and $<2.5 \mathrm{mIU} / \mathrm{L})$ and a free $\mathrm{T} 4$ below the 10th percentile $(6,13)$. This percentile corresponded to $11.76 \mathrm{pmol} / \mathrm{L}$. In line with previous studies, we tested an alternative range to define normal maternal TSH plasma levels in the assessment of hypothyroxinemia (TSH levels $>0.4$ $\mathrm{mIU} / \mathrm{L}$ or $<4.0 \mathrm{mIU} / \mathrm{L})(6,8)$. Thyroid parameters were measured after delivery, and parents were not informed about the results of the tests, except one clinical case that was excluded from this study.

Child's problem behavior. To assess the child's problem behavior, the CBCL for ages $1 \frac{1}{2}-5$ y was used (14). The CBCL consists of 99 items by which a standardized rating of behavioral and emotional problems of the children can be obtained. Two broad groupings of syndromes are scored: internalizing (anxiety, sadness, and withdrawn) and externalizing (attention problems and aggressive behavior). Five Diagnostic and Statistical Manual of Mental Disorder (DSM)-oriented scales consistent with DSM diagnostic categories were derived and used for additional analyses: affective, anxiety, pervasive developmental, attention deficit/hyperactivity, and oppositional defiant problems. The CBCL is a valid instrument to measure the degree of behavioral and emotional problems of children at young age. The version used in this study is a revision of CBCL/2-3 y and is specific for preschoolers but aims at a slightly wider age range than the previous version. It can be used to define the externalizing problems in children as young as $12 \mathrm{mo}(15)$ and has been previously used to define the internalizing and externalizing problems at the age of $18 \mathrm{mo}$ (16). In addition, there is a longitudinal correlation between scales of the CBCL/1 1/2-5 y and the CBCL/4-18 y (14). Mesman and Koot (17) showed that the internalizing and externalizing problems at 2-3 y increased the risk of similar problems at 10-11 y and externalizing problems predicted DSM diagnosis of Attention Deficit/Hyperactivity Disorders and Oppositional Defiant Disorders. According to the CBCL manual, 98th percentile of the sample was used to define clinical cut-off (corresponding scores at 3 y: 8.4 for attention deficit/hyperactivity and 7.2 for oppositional defiant problems). Based on this cut-off, 79 children $(2.1 \%)$ had attention deficit/ hyperactivity problems at $1 \frac{1}{2} \mathrm{y}$. Only 18 children $(0.5 \%)$ had scores above clinical cut-off for oppositional deviant problems at $1 \frac{1}{2} \mathrm{y}$. These numbers were $72(2.3 \%)$ and $81(2.2 \%)$ at 36 mo. These categories define children with high levels of attention deficit/hyperactivity and oppositional defiant problems and are not clinical diagnoses.

The CBCL was completed mostly by mothers when the children were $1 \frac{1}{2}$ $\mathrm{y}$ (mean age $=18.4 \mathrm{mo}, \mathrm{SD}=1.0$ ). Both mothers and fathers completed the $\mathrm{CBCL}$ again at the age of $3 \mathrm{y}$ (mean age $=36.7 \mathrm{mo}, \mathrm{SD}=1.4$ and mean age $=36.9 \mathrm{mo}, \mathrm{SD}=1.4)$. The correlation coefficients $(r)$ between mother and father ratings of internalizing and externalizing scales at 3 y were 0.56 and 0.57 . These numbers were very close to the mean correlation $(r=0.60)$ between two parents assessing the child's emotion and behavior in the same setting reported in a review (18). The intraclass correlation coefficient (ICC) for mother reported CBCL at $1 \frac{1 / 2}{2}$ and 3 y was 0.72 . The ICC for mother and father reported CBCL at 3 y was 0.73 .

Covariates. We considered the following variables as potential confounders: Apgar score, GA and weight at birth, maternal psychopathology, cigarette smoking during pregnancy, and educational level $(10,19-21)$. We also controlled for the GA at the time of thyroid assessments and child's age when the CBCL was completed.

During enrollment, information on maternal age, parity, maternal educational level, and ethnicity of the child were obtained. Maternal smoking was assessed twice, at the time of enrollment and the 30th week of gestation. The
Brief Symptom Inventory, a validated self-report questionnaire with 53 items, was applied to assess maternal psychopathology in mid pregnancy. We used the Global Severity Index as an indicator of psychopathological problems (22).

The child's national origin was defined based on the origin of parents and grandparents and categorized into Dutch, Moroccan, Turkish, Surinamese, Antillean, other Western, or other non-Western ethnicity. Information on Apgar scores 1 and 5 min after birth, birth weight and mode of delivery was derived from medical records. GA of the child at birth was defined based on fetal ultrasound measures.

Data analysis. We used independent $t$ tests, Mann-Whitney $U$ tests and $\chi^{2}$ statistics to compare characteristics of children included in the analysis with those who were excluded.

CBCL internalizing and externalizing scores were the dependent variables and analyzed primarily as continuous variables. First, we performed multiple linear regressions to assess whether maternal thyroid function is associated with the child's internalizing and externalizing scores at the age of $1 \frac{1 / 2}{2}$ and $3 \mathrm{y}$. The determinants were maternal plasma levels of TSH, free and total T4. We divided them by their SD to enable comparison. We tested the normal distribution of the residuals in the analyses with TSH (23). To avoid multiple testing, we further explored our results only in case of an association with broadband scale (post hoc analyses). To this aim, we used the following DSM-oriented subscales of the CBCL: attention deficit/hyperactivity and oppositional defiant problems. Because of the small number of children with clinical attention deficit/hyperactivity and oppositional defiant problems in general population both DSM-oriented subscales were analyzed as continuous variable. Of the tested variables, only maternal age, educational level and psychopathology, child's gender and ethnicity, mode of delivery and GA at the time of thyroid sampling were retained as confounders, based on the change-in-estimate method (5\% change criterion) (24). Significance of quadratic terms of thyroid determinants was also examined because of possible nonlinear relationship $(7,25)$.

CBCL scores, reported by two informants and at two time points, are correlated and assess the same construct. Therefore, we analyzed the overall outcome (mother- and father-report internalizing and externalizing scores at $1 \frac{1}{2}$ and 3 y), using a Generalized Estimating Equations (GEE) procedure to get to a more precise effect estimate and to reduce the error derived from multiple comparisons (type I error) (26). Any difference between two informants and a possible time trend are not easily interpretable in such a combined model.

Nonresponse analyses. Of 4856 pregnant women with data on thyroid parameters, 3736 completed the CBCL for their children. The children whose mother did not complete the CBCL $(n=1120,23.1 \%)$ were more likely to have non-Dutch national origins [64.4 versus $34.5 \%$ for the children with CBCL data, $\left.x^{2}=290.2(1), p<0.001\right]$. Mothers of nonresponders group were younger than mothers of the children with CBCL data (mean difference $=3.2 \mathrm{y} ; 95 \% \mathrm{CI}=2.9,3.5 ; p<0.001)$, less educated $[42.3 \%$ primary level versus $\left.16.0 \%, x^{2}=363.5(2), p<0.001\right]$, and were more likely to continue smoking during pregnancy [25.9 versus $14.9 \%, x^{2}=64.1(2), p<$ $0.001]$.

\section{RESULTS}

The characteristics of the children and their mothers are summarized in Table 1. A total of $8.8 \%$ of the mothers fulfilled the criteria for hypothyroxinemia during early pregnancy. By using the alternative range for maternal TSH (0.4-4.0 $\mathrm{mIU} / \mathrm{L})$, this percentage changed to 9.8 . The range for the thyroid parameters were as follows: TSH, $0.0-33.9$ $\mathrm{mIU} / \mathrm{L}$; total T4, 63.3-380.0 nmol/L; and free T4, 6.4-94.6 $\mathrm{pmol} / \mathrm{L}$. The mean (SD) of attention deficit/hyperactivity and oppositional defiant problem scores at $3 \mathrm{y}$ were 0.3 .0 (2.3) and 2.9 (2.2). Maternal age was negatively associated with CBCL externalizing scores at 3 y $(B=-3.7$ per year of maternal age; $95 \%$ CI: $-0.14,-0.05 ; p<0.001)$. Non-Dutch national origin was associated with an increased risk of externalizing scores at 3 y $(B=1.93 ; 95 \% \mathrm{CI}, 1.35,2.51 ; p<0.001)$. Mothers with only primary education had children with higher externalizing scores at 3 y $(B=1.79 ; 95 \% \mathrm{CI}, 1.10,2.49 ; p<$ $0.001)$.

In univariate analysis, there were no differences between the mean values of maternal plasma levels of TSH, free T4, 
Table 1. Baseline characteristics of subjects $(\mathrm{n}=3736)$

\begin{tabular}{|c|c|}
\hline & Mean $(\mathrm{SD}) *$ \\
\hline \multicolumn{2}{|l|}{ Maternal characteristics } \\
\hline Age at the time of enrollment $(y)$ & $30.9(4.5)$ \\
\hline Parity, primipara $(\%)$ & 60.0 \\
\hline \multicolumn{2}{|l|}{ Educational level (\%) } \\
\hline Primary & 16.0 \\
\hline Secondary & 52.4 \\
\hline High & 31.6 \\
\hline \multicolumn{2}{|l|}{ Smoking during pregnancy $(\%)$} \\
\hline Never & 75.6 \\
\hline Until pregnancy was known & 9.5 \\
\hline Continued in pregnancy & 14.9 \\
\hline Overall psychopathology score $\dagger(\mathrm{QR})$ & $0.13(0.06,0.29)$ \\
\hline $\mathrm{TSH}(\mathrm{mIU} / \mathrm{L})$ & $1.6(1.4)$ \\
\hline Total T4 (nmol/L) & $145.6(31.5)$ \\
\hline Free T4 (pmol/L) & $15.3(3.7)$ \\
\hline Hypothyroxinemia (\%) & 8.8 \\
\hline \multicolumn{2}{|l|}{ Child characteristics } \\
\hline Male gender $(\%)$ & 49.9 \\
\hline \multicolumn{2}{|l|}{ Ethnicity $(\%)$} \\
\hline Dutch & 65.5 \\
\hline Moroccan/Turkish & 9.7 \\
\hline Surinamese/Antillean & 7.3 \\
\hline Other Western & 10.0 \\
\hline Other non-Western & 7.5 \\
\hline Birth weight (g), (QR) & $3460(3100,3800)$ \\
\hline GA at birth (wk), (QR) & $40.1(39.1,41.0)$ \\
\hline Apgar score 1 min $(\mathrm{QR})$ & $9(8,9)$ \\
\hline Apgar score 5 min $(\mathrm{QR})$ & $10(9,10)$ \\
\hline \multicolumn{2}{|l|}{ Mode of delivery $(\%)$} \\
\hline Spontaneous vaginal & 71.1 \\
\hline Instrumental vaginal & 15.9 \\
\hline Cesarean section & 13.0 \\
\hline \multicolumn{2}{|l|}{ Internalizing behavioral scores } \\
\hline Mother report, $1 \frac{1}{2} \mathrm{y}$ & $5.0(4.6)$ \\
\hline Mother report, $3 \mathrm{y}$ & $5.0(4.8)$ \\
\hline Father report, $3 \mathrm{y}$ & $5.2(4.9)$ \\
\hline \multicolumn{2}{|l|}{ Externalizing behavioral scores } \\
\hline Mother report, $1 \frac{1}{2} \mathrm{y}$ & $10.6(6.6)$ \\
\hline Mother report, $3 \mathrm{y}$ & $8.4(6.2)$ \\
\hline Father report, $3 \mathrm{y}$ & $9.2(6.4)$ \\
\hline
\end{tabular}

Numbers denotes children included in one or more analyses.

* Unless otherwise indicated.

$\dagger$ Global Severity Index as measured by the Brief Symptom Inventory.

$\mathrm{QR}$, quartile range. and total T4 in groups of children with and without attention deficit/hyperactivity or oppositional defiant problems (numbers are not shown).

Table 2 summarizes the association between maternal thyroid function and internalizing scores in the offspring. Maternal TSH was not associated with internalizing scores reported by mothers. Higher levels of TSH did not increase the risk of a high internalizing score in children, as demonstrated by the GEE approach using internalizing scores reported by father and mother at $1 \frac{1}{2}$ and 3 y $(B=0.10$ per SD of TSH; $95 \% \mathrm{CI}$, $-0.01,0.21 ; p=0.07)$. Similarly, free and total T4 did not predict the internalizing scores of children. Looking at $1 \frac{1}{2}$ and 3 y separately, we found that TSH levels were not associated with higher internalizing scores at $1 \frac{1}{2}$ and $3 \mathrm{y}$, reported by mothers $(B=0.05$ per SD of TSH; $95 \% \mathrm{CI},-0.10,0.20 ; p=$ 0.52 and $B=0.01$ per SD of $\mathrm{TSH} ; 95 \% \mathrm{CI},-0.16,0.16 ; p=$ 0.96).

Table 3 shows the associations between maternal thyroid parameters and externalizing scores in children. Higher plasma levels of TSH were consistently associated with externalizing scores. Higher TSH levels increased the risk of a high externalizing score at $3 \mathrm{y}$ as reported by fathers $(B=0.26$ per SD of TSH; 95\% CI, 0.02, 0.50; $p=0.03$ ). But more importantly, analyses with GEE confirmed a positive association between TSH levels and externalizing scores $(B=0.22$ per SD of TSH; 95\% CI, 0.04, 0.40; $p=0.02$ ), combining mother- and father-report externalizing scores at $1 \frac{1}{2}$ and $3 \mathrm{y}$. Maternal free and total T4 were not associated with children's externalizing scores at $1 \frac{1}{2}$ and $3 \mathrm{y}$. Analyzing mother-report externalizing scores at $1 \frac{1}{2}$ and 3 y separately showed that maternal TSH levels were associated with higher externalizing scores, but neither of these association was statistically significant $(B=0.20$ per SD of TSH; $95 \% \mathrm{CI},-00.02,0.42$ and $B=0.14$ per SD of TSH; $95 \% \mathrm{CI},-0.07,0.36)$. Comparing these findings with the results of GEE methods confirmed that pooling the scores from the reports of different informants in different times increases the precision of estimate as reflected by narrower CIs. The posthoc analyses showed that higher plasma levels of TSH were related to higher scores on attention deficit/hyperactivity ( $B=0.08$ per SD of TSH; $95 \%$ CI, $0.01,0.15$, and 0.05 ) and oppositional defiant problems in children $(B=0.08$ per SD of TSH; $95 \% \mathrm{CI}, 0.02,0.14$, and $0.01)$ in combined analyses.

Table 2. Maternal thyroid function during pregnancy and internalizing scores in children within Generation $R$ cohort

\begin{tabular}{|c|c|c|c|c|c|c|}
\hline \multirow[b]{3}{*}{$\begin{array}{c}\text { Thyroid } \\
\text { parameters }\end{array}$} & \multicolumn{6}{|c|}{ Internalizing scores } \\
\hline & \multicolumn{4}{|c|}{ One parent report } & \multicolumn{2}{|c|}{ Both parents report } \\
\hline & Total $(n)$ & $\begin{array}{l}\text { Mother report* } \\
\left(11 \frac{1}{2} \text { and } 3 \mathrm{y}\right) \\
B(95 \% \mathrm{CI}), p\end{array}$ & Total $(n)$ & $\begin{array}{c}\text { Father report }(3 \mathrm{y}) \\
B(95 \% \mathrm{CI}), p\end{array}$ & Total $(n)$ & $\begin{array}{l}\text { Mother and father } \\
\text { report }\left(1 \frac{1}{2} \text { and } 3 \mathrm{y}\right) \\
B(95 \% \mathrm{CI}), p\end{array}$ \\
\hline $\mathrm{TSH}($ per SD $) \dagger$ & 3677 & $0.02(-0.09,0.11), 0.71$ & 2618 & $0.24(0.07,0.42), 0.01$ & 3682 & $0.10(-0.01,0.21), 0.07$ \\
\hline Free T4 (per SD) $\dagger$ & 3702 & $0.03(-0.11,0.17), 0.70$ & 2635 & $-0.07(-0.25,0.12), 0.47$ & 3707 & $0.01(-0.13,0.15), 0.91$ \\
\hline Total T4 (per SD) $\dagger$ & 3719 & $0.11(-0.02,0.24), 0.09$ & 2652 & $0.06(-0.12,0.25), 0.51$ & 3724 & $0.09(-0.04,0.22), 0.19$ \\
\hline
\end{tabular}

Total of children in one or more analyses is 3736. $B$ gives the estimate of increase in CBCL score per SD of thyroid parameters. Models were adjusted for maternal age, educational level and psychopathology, child's gender, ethnicity, mode of delivery, and GA at the time of maternal thyroid sampling. Other variables were tested as potential confounders but did not change the effect estimate (see the Methods and Materials section).

* At the $1 \frac{1}{2}$ y assessment, $<10 \%$ of informants were the primary caregivers other than mothers.

$\dagger$ SD of TSH, 1.43; SD of free T4, 3.48; and SD of total T4, 31.31 (SDs are calculated in whole sample). 
Table 3. Maternal thyroid function during pregnancy and externalizing scores in children within Generation $R$ cohort

\begin{tabular}{|c|c|c|c|c|c|c|}
\hline \multirow[b]{3}{*}{$\begin{array}{c}\text { Thyroid } \\
\text { parameters }\end{array}$} & \multicolumn{6}{|c|}{ Externalizing scores } \\
\hline & \multicolumn{4}{|c|}{ One parent report } & \multicolumn{2}{|c|}{ Both parents report } \\
\hline & Total $(n)$ & $\begin{array}{l}\text { Mother-report* } \\
\left(11 \frac{1}{2} \text { and } 3 \mathrm{y}\right) \\
B(95 \% \mathrm{CI}), p\end{array}$ & Total $(n)$ & $\begin{array}{c}\text { Father report (3 y) } \\
B(95 \% \mathrm{CI}), p\end{array}$ & Total $(n)$ & $\begin{array}{c}\text { Mother and father report } \\
\left(11 \frac{1}{2} \text { and } 3 \text { y }\right) \\
B(95 \% \text { CI }), p\end{array}$ \\
\hline $\mathrm{TSH}($ per SD $) \dagger$ & 3681 & $0.15(-0.03,0.33), 0.10$ & 2616 & $0.26(0.02,0.50), 0.03^{*}$ & 3687 & $0.22(0.04,0.40), 0.02^{*}$ \\
\hline Free T4 (per SD) $\dagger$ & 3706 & $0.02(-0.16,0.20), 0.81$ & 2633 & $-0.14(-0.39,0.11), 0.27$ & 3712 & $-0.02(-0.16,0.20), 0.80$ \\
\hline Total T4 (per SD) $\dagger$ & 3723 & $0.15(-0.04,0.34), 0.13$ & 2650 & $0.08(-0.17,0.33), 0.55$ & 3729 & $0.12(-0.06,0.30), 0.19$ \\
\hline
\end{tabular}

Total of children in one or more analyses is 3736. $B$ gives the estimate of increase in CBCL score per SD of thyroid parameters. Models were adjusted for maternal age, educational level and psychopathology, child's gender, ethnicity, mode of delivery, and GA at the time of maternal thyroid sampling. Other variables were tested as potential confounders but did not change the effect estimate (see the Methods and Materials section).

* At the $1 \frac{1}{2} \mathrm{y}$ assessment, $<10 \%$ of informants were the primary caregivers other than mothers.

$\dagger$ SD of TSH, 1.43; SD of free T4, 3.48; and SD of total T4, 31.31 (SDs are calculated in whole sample).

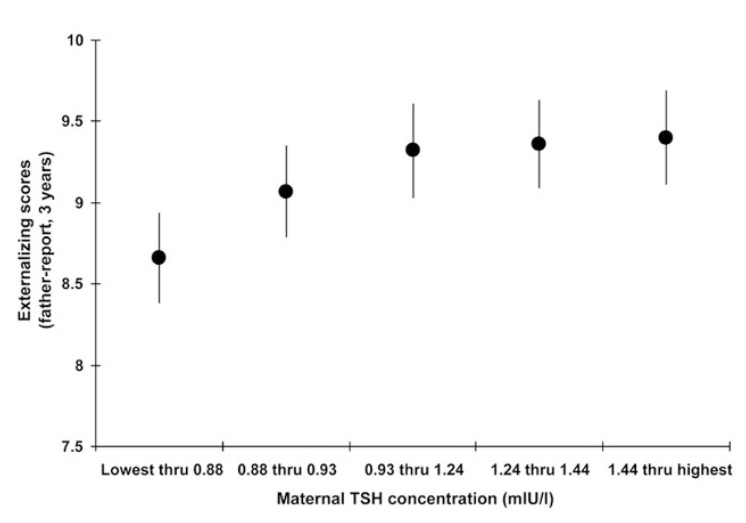

Figure 1. Maternal TSH and externalizing behavioral mean scores in children at $3 \mathrm{y}$ (father report), The Generation R Study. *Error bars are SE. **The children were divided in five equal groups based on 20th, 40th, 60th, and 80th percentile of maternal TSH.

Figure 1 illustrates the unadjusted association between TSH and externalizing scores at $36 \mathrm{mo}$, reported by fathers. The children were divided in five equal groups based on 20th, 40th, 60th, and 80th percentile of the maternal TSH. As illustrated in Figure 1, externalizing mean scores increased with higher TSH levels. However, there is little evidence for a clear threshold for TSH in the association with externalizing scores.

Maternal hypothyroxinemia was not associated with higher internalizing scores at $1 \frac{1}{2}$ and 3 y $(B=-0.19$ for hypothyroxinemic mothers; $95 \% \mathrm{CI},-0.75$ and $0.37 ; p=0.51$ ). Similarly, there was no association between maternal hypothyroxinemia and externalizing scores $(B=0.17$ for hypothyroxinemic mothers; $95 \% \mathrm{CI},-0.53$ and $0.87 ; p=0.64)$. With the alternative cut-off for the definition of hypothyroxinemia, we obtained similar results. Adding quadratic terms of thyroid parameters to the model did not improve the model's fit and support the notion of a nonlinear association between maternal thyroid parameters and problem behavior of children (data not shown).

\section{DISCUSSION}

In this study, higher plasma levels of maternal TSH in the first half of pregnancy predicted the externalizing scores in the offspring. An effect of maternal TSH on the internalizing scores was less clear but cannot be ruled out in this study. Plasma levels of free and total T4 in the mothers were not associated with internalizing and externalizing scores in their children.

Results from molecular $(4,5)$ and clinical (7) observations provide evidence for a prominent role of thyroid hormones in brain development. Vermiglio et al. (8) showed that maternal hypothyroxinemia and TSH levels during pregnancy are associated with attention-deficit hyperactivity disorders in children. The retrospective design of the study and the small sample size make it difficult to infer a causal relationship from these results. Kooistra et al. (20) demonstrated that maternal free T4 but not TSH predicts the behavior of neonates. They assessed the behavior of the child at the age of $3 \mathrm{wk}$, which is too early to interpret the outcome as behavioral problems. In this study, we showed that maternal TSH can predict children's externalizing scores. Further exploratory analyses extended this by showing an association between maternal thyroid parameters and attention deficit/hyperactivity and oppositional deviant problems in children.

Our results support the evidence that TSH is a good indicator of thyroid function problems because of the delicate feedback mechanism of pituitary. Mild increases in TSH, as a stimulatory mechanism for thyroid hormone secretion, can signal low levels of maternal thyroid hormones (27). These may lead to impaired fetal brain development and subsequent externalizing problems. However, from the results, we cannot infer that maternal TSH affects internalizing and externalizing scores differently. First, the effect estimates were very similar with largely overlapping confidence intervals. Second, the overall association between TSH and internalizing scores just failed to reach the significant level. We must be careful not to rule out an association with internalizing scores. However, the role of thyroid hormones in the normal development of neural structures in the cerebral cortex (3) makes an effect on the externalizing problem scores particularly plausible because cortical structures are responsible for the regulation of inhibitory processes (28). Impairments in the control system may lead to deficits in executive functions as seen in externalizing problems (29). Our data showed that maternal TSH was consistently associated with higher externalizing scores as reported by mother and father at $1 \frac{1 / 2}{2}$ and $3 \mathrm{y}$, with similar $B$ and overlapping CI. When we combined these data, using 
GEE approach, we gained power. This is comparable with a meta-analysis of randomized clinical trials in which nonsignificant findings from different trials are combined to obtain one overall effect estimate, which can be significant. However, in this study, we combined repeated measures of behavior in the same children.

Despite some evidence from previous epidemiological studies $(8,9)$, a valid indicator of maternal thyroid function during pregnancy remains a challenge. As T3 in the brain of the fetus is directly derived from T4 (27), its measurement in maternal plasma has limited value in the diagnosis of thyroid dysfunction, and the active biologic agent is not the best marker of the underlying dysfunction. Commonly, maternal thyroid insufficiency during pregnancy is defined by high plasma levels of TSH; but Pop et al. $(7,8)$ presented free T4 as a predictor of externalizing scores in the child. Other studies suggest that $\mathrm{TSH}$, although not the biologically active hormone in the brain, is a more sensitive indicator of maternal thyroid dysfunction. This is consistent with our results showing that maternal TSH predicted problem behavior of the child; whereas, we found no evidence for an effect of low maternal free and total T4 during pregnancy. This may imply that the best surrogate indicator for maternal thyroid dysfunction can be different in the general population than in clinical samples.

In this study, we found similar effect sizes for maternal education and TSH levels on externalizing scores (both $r^{2}=$ 0.03 ). For comparison, in medical science, the effect sizes of a magnitude between 0.01 and 0.04 are sometimes considered as "dramatic" (30), whereas the same effect sizes in the field of child's behavior are typically considered "small."

Our study has several strengths. Few population-based studies investigated prospectively the effect of maternal thyroid function on problem behavior of the offspring. We measured maternal thyroid parameters before the 18th wk of gestation, as recommended in the literature $(7,10)$. The child's behavior was assessed at two time points and by both parents to reduce the informant effect (31).

The participation rate in this study was high but the possibility of selection bias remains, as the nonrespondents differed from participants. We can only speculate whether the relationship between TSH and externalizing scores was different in mothers lost to follow-up. However, we certainly lost some statistical power. Another limitation of this study was that the full effect of both time and informant on the outcome could not be shown, as the fathers were approached only when the children were 3 y to minimize the burden on parents. Moreover, not all items of the DSM scales of CBCL are applicable to all ages. However, an instrument like CBCL that covers a relatively wide age range makes findings across ages easily comparable. In addition, these scales do not provide a diagnostic category but address a continuous trait in children. We did not measure the iodine levels in maternal blood and in the diet, a factor which can affect both thyroid hormones and the brain structure of the child (8).

The positive linear association between maternal plasma TSH levels and externalizing scores of children suggests that subtle variation of maternal thyroid function in the general population impacts on fetal brain development, which determines behavioral and emotional problems later in life.

Acknowledgments. We acknowledge the contribution of general practitioners, hospitals, midwifes, and pharmacies in Rotterdam. The contribution of Mr. H. van Toor, laboratory technician, is highly appreciated.

\section{REFERENCES}

1. Man EB, Jones WS 1969 Thyroid function in human pregnancy. V. Incidence of maternal serum low butanol-extractable iodines and of normal gestational TBG and TBPA capacities; retardation of 8-month-old infants. Am J Obstet Gynecol 104:898-908

2. Man EB, Serunian SA 1976 Thyroid function in human pregnancy. IX. Development or retardation of 7-year-old progeny of hypothyroxinemic women. Am J Obstet Gynecol 125:949-956

3. Zoeller RT, Rovet J 2004 Timing of thyroid hormone action in the developing brain: clinical observations and experimental findings. J Neuroendocrinol 16:809-818

4. de Escobar GM, Obregon MJ, del Rey FE 2007 Iodine deficiency and brain development in the first half of pregnancy. Public Health Nutr 10:1554-1570

5. de Escobar GM, Obregón MJ, del Rey FE 2004 Maternal thyroid hormones early in pregnancy and fetal brain development. Best Pract Res Clin Endocrinol Metab 18:225-248

6. Abalovich M, Amino N, Barbour LA, Cobin RH, De Groot LJ, Glinoer D, Mandel SJ, Stagnaro-Green A 2007 Management of thyroid dysfunction during pregnancy and postpartum: an Endocrine Society Clinical Practice Guideline. J Clin Endocrinol Metab 92:S1-S47

7. Haddow JE, Palomaki GE, Allan WC, Williams JR, Knight GJ, Gagnon J, O’Heir CE, Mitchell ML, Hermos RJ, Waisbren SE, Faix JD, Klein RZ 1999 Maternal thyroid deficiency during pregnancy and subsequent neuropsychological development of the child. N Engl J Med 341:549-555

8. Vermiglio F, Lo Presti VP, Moleti M, Sidoti M, Tortorella G, Scaffidi G, Castagna MG, Mattina F, Violi MA, Crisà A, Artemisia A, Trimarchi F 2004 Attention deficit and hyperactivity disorders in the offspring of mothers exposed to mild-moderate iodine deficiency: a possible novel iodine deficiency disorder in developed countries. J Clin Endocrinol Metab 89:6054-6060

9. Pop VJ, Brouwers EP, Vader HL, Vulsma T, van Baar AL, de Vijlder JJ 2003 Maternal hypothyroxinaemia during early pregnancy and subsequent child development: a 3-year follow-up study. Clin Endocrinol (Oxf) 59:282-288

10. Pop VJ, Kuijpens JL, van Baar AL, Verkerk G, van Son MM, de Vijlder JJ, Vulsma T, Wiersinga WM, Drexhage HA, Vader HL 1999 Low maternal free thyroxin concentrations during early pregnancy are associated with impaired psychomotor development in infancy. Clin Endocrinol (Oxf) 50:149-155

11. Jaddoe VW, Bakker R, van Duijn CM, van der Heijden AJ, Lindemans J, Mackenbach JP, Moll HA, Steegers EA, Tiemeier H, Uitterlinden AG, Verhulst FC, Hofman A 2007 The Generation R Study Biobank: a resource for epidemiological studies in children and their parents. Eur J Epidemiol 22:917-923

12. Jaddoe VW, van Duijn CM, van der Heijden AJ, Mackenbach JP, Moll HA, Steegers EA, Tiemeier H, Uitterlinden AG, Verhulst FC, Hofman A 2008 The Generation R Study: design and cohort update until the age of 4 years. Eur J Epidemiol 23:801811

13. Oken E, Braverman LE, Platek D, Mitchell ML, Lee SL, Pearce EN 2009 Neonatal thyroxine, maternal thyroid function, and child cognition. J Clin Endocrinol Metab 94:497-503

14. Achenbach TM, Rescorla LA 2000 Manual for ASEBA Preschool Forms \& Profiles. University of Vermont, Research Center for Children, Youth and Families, Burlington, pp 30-96

15. van Zeijl J, Mesman J, Stolk MN, Alink LR, van Ijzendoorn MH, Bakermans Kranenburg MJ, Juffer F, Koot HM 2006 Terrible ones? Assessment of externalizing behaviors in infancy with the Child Behavior Checklist. J Child Psychol Psychiatry 47:801-810

16. Roza SJ, van Batenburg-Eddes T, Steegers EA, Jaddoe VW, Mackenbach JP, Hofman A, Verhulst FC, Tiemeier H 2010 Maternal folic acid supplement use in early pregnancy and child behavioural problems: The Generation R Study. Br J Nutr 103:445-452

17. Mesman J, Koot HM 2001 Early preschool predictors of preadolescent internalizing and externalizing DSM-IV diagnoses. J Am Acad Child Adolesc Psychiatry 40:1029-1036

18. Achenbach TM, McConaughy SH, Howell CT 1987 Child/adolescent behavioral and emotional problems: Implications of cross-informant correlations for situational specificity. Psychol Bull 101:213-232

19. Pop VJ, de Vries E, van Baar AL, Waelkens JJ, de Rooy HA, Horsten M, Donkers MM, Komproe IH, van Son MM, Vader HL 1995 Maternal thyroid peroxidase antibodies during pregnancy: a marker of impaired child development? J Clin Endocrinol Metab 80:3561-3566

20. Kooistra L, Crawford S, van Baar AL, Brouwers EP, Pop VJ 2006 Neonatal effects of maternal hypothyroxinemia during early pregnancy. Pediatrics 117:161-167

21. Cleary-Goldman J, Malone FD, Lambert-Messerlian G, Sullivan L, Canick J, Porter TF, Luthy D, Gross S, Bianchi DW, D'Alton ME 2008 Maternal thyroid hypofunction and pregnancy outcome. Obstet Gynecol 112:85-92 
22. Derogatis LR 1993 Brief Symptom Inventory (BSI): Administration, Scoring and Procedures. National Computer Systems Inc, Minneapolis, pp10-22

23. Altman DG 1994 Practical Statistics for Medical Research. Chapman \& Hall, London, pp 303-304

24. Rothman KJ, Greenland S, Lash TL 2008 Modern Epidemiology. Lippincott-Raven Publishers, Philadelphia, pp 261-263

25. Evans IM, Pickard MR, Sinha AK, Leonard AJ, Sampson DC, Ekins RP 2002 Influence of maternal hyperthyroidism in the rat on the expression of neuronal and astrocytic cytoskeletal proteins in fetal brain. J Endocrinol 175:597-604

26. Rothman KJ 1990 No adjustments are needed for multiple comparisons. Epidemiology 1:43-46

27. Lavado-Autric R, Ausó E, García-Velasco JV, Arufe Mdel C, Escobar del Rey F, Berbel P, Morreale de Escobar G 2003 Early maternal hypothyroxinemia alters histogenesis and cerebral cortex cytoarchitecture of the progeny. J Clin Invest 111:1073-1082

28. Campbell SB, Shaw DS, Gilliom M 2000 Early externalizing behavior problems: toddlers and preschoolers at risk for later maladjustment. Dev Psychopathol 12:467488

29. Sergeant JA, Geurts H, Oosterlaan J 2002 How specific is a deficit of executive functioning for attention-deficit/hyperactivity disorder? Behav Brain Res 130:3-28

30. Dallaire DH, Weinraub M 2007 Infant-mother attachment security and children's anxiety and aggression at first grade. J Appl Dev Psychol 28:477-492

31. Rowe DC, Kandel D 1997 In the eye of the beholder? Parental ratings of externalizing and internalizing symptoms. J Abnorm Child Psychol 25:265-275 